\title{
Dimensão ética do fazer cotidiano no processo de formação do enfermeiro
}

\author{
THE ETHIC DIMENSION OF DAILY TASKS IN THE FORMATION PROCESS OF NURSES \\ DIMENSIÓN ÉTICA DEL HACER COTIDIANO EN EL PROCESO \\ DE FORMACIÓN DEL ENFERMERO
}

\author{
Josicélia Dumêt Fernandes ${ }^{1}$, Darci de Oliveira Santa Rosa ${ }^{2}$, \\ Therezinha Teixeira Vieira ${ }^{3}$, Dora Sadigursky ${ }^{4}$
}

\section{RESUMO}

O presente artigo teórico teve como objeto de estudo a dimensão ética do processo de formação do enfermeiro, considerando a implementação das Diretrizes Curriculares Nacionais dos Cursos de Enfermagem. Fundamentou-se nos pressupostos da ética, suas relações com a implementação da mudança no processo de formação do enfermeiro, tomando como referência fatores do fazer ético na formação, buscando oportunizar reflexões e contribuir com os rumos da educação em enfermagem. Concluiu-se que a dimensão ética na formação do enfermeiro envolve valores que permeiam as relações entre os sujeitos desse processo ea própria natureza. 0 estudo recomenda a necessidade de transformação da prática do educando/educador e do modelo curricular constituído, apontando elementos que indicam que a preocupação com a ética no desenvolvimento do currículo não se limita ao ensino em uma disciplina, mas perpassa todas as práticas que se dão no interior do processo educativo.

\section{DESCRITORES}

Educação em enfermagem.

Ética de enfermagem.

Currículo.

\begin{abstract}
This theoretical article had as its object of study the ethic dimension of the formation process of nurses taking in consideration the National Curricular Directives for Nursing Courses. It was based on the presuppositions of ethics and their relationship with the implementation of changes in the formation process of nurses, using as reference elements of ethical behavior in the formation and attempting to bring the reflection to current times and thus contribute to define a direction to Nursing education. It was concluded that the ethical dimension in the formation of nurses involves values that permeate the relations between the subjects of this process and nature itself. The study points out the need to transform the practices of students and teachers and change the current curriculum f framework, highlighting elements that indicate that the concern with ethics when developing the curriculum framework is not limited to how a discipline is taught, but pass through as practices that take place in the education process.
\end{abstract}

\section{KEY WORDS}

Education, nursing.

Ethics, nursing.

Curriculum.

\section{RESUMEN}

El presente artículo teórico tuvo como objeto de estudio la dimensión ética del proceso de formación del enfermero, considerando la implementación de las Directrices Curriculares Nacionales del Pregrado en Enfermería. Se fundamentó en las premisas de la ética, sus relaciones con la implementación del cambio en el proceso de formación del enfermero, tomando como referencia factores del hacer ético en la formación, buscando oportunidades de reflexiones y contribuir con los rumbos de la educación en enfermería. Se concluye que la dimensión ética en la formación del enfermero involucra valores que permean las relaciones entre los sujetos de ese proceso y la propia naturaleza. El estudio recomienda la necesidad de transformación de la práctica del educando/educador y del modelo curricular constituido, apuntando elementos que indican que la preocupación con la ética en el desarrollo del currículo no se limita a la enseñanza en una disciplina, sino que atraviesa todas las prácticas que se dan al interior del proceso educativo.

\section{DESCRIPTORES}

Educación en enfermería.

Ética de enfermería.

Curriculum.

\footnotetext{
${ }^{1}$ Doutora em Enfermagem. Professora Titular da Escola de Enfermagem da Universidade Federal da Bahia (UFBA). Pesquisadora do CNPq. Vice-Líder do Grupo de Estudos e Pesquisas em Educação, Ética e Exercício de Enfermagem (EXERCE) da Escola de Enfermagem da UFBA. Membro da Sociedade Brasileira de Bioética. Salvador, BA, Brasil. dumet@ufba.br ${ }^{2}$ Doutora em Enfermagem. Professora Adjunta da Escola de Enfermagem da Universidade Federal da Bahia. Líder do Grupo de Estudos e Pesquisas em Educação, Ética e Exercício de Enfermagem (EXERCE) da Escola de Enfermagem da UFBA. Membro da Sociedade Brasileira de Bioética. Salvador, BA, Brasil. darcisantarosa@gmail.com ${ }^{3}$ Livre Docente em Enfermagem. Professora Titular Aposentada da Escola de Enfermagem da Universidade Federal da Bahia. Membro do Grupo de Estudos e Pesquisas em Educação, Ética e Exercício de Enfermagem (EXERCE). Membro da Sociedade Brasileira de Bioética. Salvador, BA, Brasil. therezinhavieira@uol.com.br ${ }^{4}$ Doutora em Enfermagem. Professora Adjunta da Escola de Enfermagem da UFBA. Líder do Grupo de Estudos e Pesquisas em Saúde Mental (GESAM). Salvador, BA, Brasil. dora@ufba.br
} 


\section{INTRODUÇÃO}

A Resolução CNE/CES № 03 de 7/11/2001(1), que define as Diretrizes Curriculares Nacionais do Curso de Graduação em Enfermagem (DCENF), vem direcionando as mudanças no processo de formação do enfermeiro. Essas Diretrizes têm sua concretude assegurada através de propostas que emergiram da mobilização da categoria numa perspectiva coletiva, cidadã e ética dos sujeitos envolvidos no processo de educação em enfermagem ${ }^{(2)}$.

As DCENF vêm exigindo uma educação mais flexível, crítica, reflexiva, versátil, constante e que busque respostas aos desafios da atenção à saúde da população. Elas indicam, pois, a necessidade da formação de um profissional capacitado para atuar com senso de responsabilidade social e compromisso com a cidadania, como promotor da saúde integral do ser humano, fundamentado nos princípios da Reforma Sanitária Brasileira e do Sistema Unico de Saúde (SUS).

As mudanças no processo de formação do enfermeiro não podem, destarte, ser pensadas sem a visualização das perspectivas éticas que constituem a base de seu desenvolvimento. Elas apontam para 0 aprender a aprender no cuidar de homens e muIheres, da infância à terceira idade, em todos os níveis de saúde, nas suas várias dimensões, através de uma formação global, crítica e integradora, produto da indissociabilidade entre ensino, pesquisa, extensão e assistência, que complete a cultura, a ética e as inovações científicas e tecnológicas ${ }^{(3)}$.

0 saber-fazer no processo de cuidar transita nos planos objetivo e simbólico e se insere na complexidade do mundo globalizado(4), 0 que implica na responsabilidade dos sujeitos envolvidos como participantes desse processo; no abandono do velho modelo; no direcionamento de novos rumos para a graduação, considerando a superação da prática docente e do modelo curricular, até então, constituído. E esta é uma tarefa, por si mesma, complexa, por suas múltiplas implicações, num mundo em que 0 avanço técnico-científico vem se dando de modo vertiginoso, atingindo de perto o ser humano no seu pensar, no seu comunicar, no seu agir, no seu ser ético.

Como qualquer atividade humana, a implementação da mudança no processo de formação do enfermeiro não é neutra. Ela se apresenta regida por valores morais, onde seus sujeitos - docentes, alunos e profissionais dos campos de práticas - assumem a responsabilidade pelo seu caminhar com qualidade, orientando suas condutas pela integridade. É um processo que implica na complexidade da forma de compreender o mundo, de reconhecer a ordem e a desordem, o uno e o diverso, a estabilidade e a mudança, enfim, a complexidade comporta as ações, as interações e as determinações que constituem o mundo dos fenômenos e, principalmente, a noção de incerteza ${ }^{(5)}$.

Entendemos que a mudança no processo de formação do enfermeiro implica em fazer escolhas ideológicas, de acordo com o modelo de ser humano e de educação que defendemos, ou seja, se desejamos uma educação que desenvolva a autonomia ou o conformismo, a tolerância ou o desprezo, o gosto pelo risco intelectual ou a busca de certezas, o pesquisar ou o dogmatismo, a solidariedade ou 0 individualismo.

0 presente estudo fundamenta-se, portanto, no entendimento de que o fazer cotidiano na implementação da mudança no processo de formação do enfermeiro aponta para a adoção de valores que busquem respostas aos desafios que se apresentam na complexidade da atenção à saúde da população.

Sob esse entendimento, este trabalho baseia-se nos pressupostos da ética e de suas relações com a realidade atual da educação em enfermagem, tendo como objeto de estudo, a dimensão ética no processo de formação do enfermeiro, considerando a implementação das Diretrizes Curriculares Nacionais dos Cursos de Enfermagem.

Nesse sentido, foram definidos os seguintes objetivos: analisar a base teórica dos princípios éticos na implementação da mudança no processo de formação do enfermeiro; explicitar as principais ações e comportamentos que instrumentalizam o fazer ético no processo de formação do enfermeiro.

0 estudo do tema em pauta assume, assim, um caráter necessário e relevante, na medida em que pretende contribuir para a construção de novas pesquisas, bem como para equacionar problemas, questões e desafios impostos pelo processo de formação do enfermeiro, servindo de subsídio para se reorientar 0 fazer e o saber no desafiante caminho mudança na educação em enfermagem.

Para o alcance de seus objetivos, o presente artigo configura-se como um estudo teórico que toma como referência alguns construtos da ética e sua relação com os fatores constituintes do fazer pedagógico, buscando promover a discussão/reflexão sobre a dimensão ética do processo de formação do enfermeiro, na perspectiva das DCENF. Ademais, ele busca contribuir com os novos rumos da educação em enfermagem. Para isso, este artigo apoia-se na revisão teórica de estudos dessa área temática.

Por esta opção e movidas pelo debate contemporâneo acerca da complexidade do tema, discutimos alguns pressupostos da ética e suas principais relações com a implementação das mudanças no processo de formação do enfermeiro. Em seguida, apresentamos considerações sobre o fazer cotidiano que instrumentaliza o processo de 
formação do enfermeiro. Esses dois momentos da apresentação são perpassados pela fundamentação teórica que oferece sustentação ao presente estudo.

\section{A ÉTICA NA IMPLEMENTAÇÃO DA MUDANCCA NO PROCESSO DE FORMAÇÃO DO ENFERMEIRO}

A indicação da mudança que se insere no bojo das DCENF apresenta reflexos no desenvolvimento e na ação coletiva e cidadã dos sujeitos envolvidos no processo de formação, o que implica na responsabilidade ético-social desses sujeitos com a educação e a saúde.

Enquanto as DCENF se constituem num conjunto de diretrizes, em forma de Resolução, a responsabilidade ético-social dos sujeitos envolvidos no processo de formação do enfermeiro se constitui num conjunto de atitudes que vão além dessas diretrizes e que estão permeadas por juízos de valores, o que significa uma ação qualificada (técnica e política) que indica, necessariamente, a superação e reconstrução do atual modo de pensar e fazer educação em enfermagem.

A responsabilidade ético-social dos sujeitos envolvidos no processo de formação passa, portanto, por uma nova proposta de trabalho acadêmico, um novo modelo de pensamento, uma re-significação do trabalho docente, um novo modo de aprender a aprender. Passa, também, pela explicitação dos saberes, das capacidades, dos esquemas de pensamento, das orientações éticas necessárias e, ainda, pelo desafio de formar um profissional crítico e reflexivo capaz de se inserir na produção dos serviços de saúde na perspectiva da consolidação do Sistema Único de Saúde, de acordo com os princípios da Reforma Sanitária brasileira.

Essas ações inserem-se no reconhecimento de que a mudança não pode ser orientada por visões e concepções de mundo que conduzem à ação pedagógica pautada apenas na dimensão técnico-instrumental. É imprescindível valorizar a dimensão crítica e criativa orientada por decisões e situações de aprendizagem a partir da própria ação dos sujeitos envolvidos, acolhendo o sentido de responsabilidade social e espontaneidade da ação ética(6).

$O$ cotidiano do processo de formação em enfermagem envolve valores que permeiam as relações entre os sujeitos desse processo e desses com a própria natureza. E isto aponta, necessariamente, pela vivência desses sujeitos no dia-dia do desenvolvimento de suas atividades, no contato estabelecido entre os mesmos e entre estes e os usuários dos serviços de saúde, na relação com os demais profissionais da área e com a comunidade em geral. Aponta, enfim, pelo modo de organizar, qualificar e dispor as ações acadêmicas em compromisso com os direitos de cidadania e nos valores sociais de solidariedade e alteridade.

A implementação da mudança exige, pois, prudência com a formação de um comportamento cotidiano ético e responsável, para o binômio educador-educando, na perspectiva da formação de atitudes imprescindíveis a todo cidadão profissional. E isto implica na utilização dos construtos teóricos dos princípios éticos que norteiam 0 processo de formação do enfermeiro, ou sejam, Beneficência - Não Maleficência, Autonomia, Responsabilidade, Liberdade, Alteridade, Solidariedade e Justiça.

A Beneficência é, antes de tudo, um princípio de cautela, alerta e prudência. É um princípio atrelado à ação de fazer o bem, de não causar danos, de favorecer a qualidade de vida. Esse princípio caracteriza-se pela ação da promoção do bem estar do outro, levando-se em conta os desejos, necessidades e os direitos de outrem ${ }^{(7)}$.

Atrelado ao princípio da Beneficência, está o da Não Maleficência que indica o dever não só do profissional, mas, também, de todo cidadão, de tentar proteger os indivíduos ou a sociedade como um todo, de todos os tipos e níveis de malefícios, quer físicos, emocionais ou sociais, além de evitar causá-los ou impor, a quem quer que seja, risco desnecessário ${ }^{(7)}$.

$\mathrm{Na}$ implementação das mudanças na educação em enfermagem, o princípio da Beneficência se caracteriza pelo reconhecimento do valor moral dos sujeitos desse processo, ou seja do docente, do discente, dos profissionais e usuários de serviços de saúde, onde todos se comprometem a avaliar riscos e benefícios potenciais (individuais e coletivos), buscando o máximo de benefícios e reduzindo ao mínimo os danos e riscos aos envolvidos e à sociedade. Não basta que professores e alunos tenham boas intenções, mas é preciso evitar situações de riscos individuais ou coletivos para si e para toda a sociedade. A Beneficência não aponta para a necessidade de o professor adotar uma atitude paternalista, decidindo o que é melhor para 0 aluno, sem levar em conta seus pensamentos ou sentimentos e, até mesmo, considerando-o como desconhecedor do conteúdo do processo ensino-aprendizagem. Não significa que as respostas devam ser dadas aos alunos para que as memorizem, nem tampouco que 0 conhecimento lhes é dado como pronto e não como uma conexão viva com a realidade deles ${ }^{(8)}$.

No exercício da Beneficência, o docente, mesmo tendo a intenção de fazer o bem, não deverá reduzir os alunos à condição de incapazes e, nesse caso, interferindo em sua liberdade de ação. Os alunos, por sua vez, não estando acostumados a exercerem a sua cidadania, aceitam sem questionamento essa realidade ${ }^{(8)}$.

Docentes e discentes exercendo o poder de produzir conhecimento, no cotidiano de suas ações, estarão reafirmando seu poder de refazer a sociedade com Beneficência e Não Maleficência; estarão ratificando sua sensibilidade aliada a uma capacidade de percepção e reflexão que vão além do domínio privado, ou seja, uma sensibilidade política a tudo que é intolerável e inaceitável no processo de formação do enfermeiro.

0 modelo de educação formal, muitas vezes, não consegue beneficiar os alunos, desativando a potencialidade 
criativa dos mesmos. Para se saber o que é bom para professores, alunos, profissionais e usuários dos serviços de saúde é necessário que se reconheça o respeito à sua própria autonomia e à do outro, evitando riscos danos aos envolvidos no processo educativo/assistencial, bem como 0 direito do cliente a essa isenção de riscos.

A Autonomia é a capacidade de autogovernar-se, de escolher, avaliar, decidir, sem restrições internas e/ou externas, ou seja, é a legislação, pelo sujeito, da sua vida e de suas atitudes de deliberação, decisão e execução; é a capacidade de ser e agir como sujeito. É um princípio fundamentado no critério ético da emancipação da razão humana, do direito sócio-político da decisão e da ação autônomas ${ }^{(7)}$.

0 princípio da Autonomia no processo de formação implica em que os sujeitos envolvidos nesse processo estejam conscientes de seus direitos e deveres. Assim, eles estabelecem, entre si, relações de respeito à vontade, à crença e aos valores morais dos envolvidos e discutem como isso deve ser desenvolvido com os demais cidadãos. Através desse princípio exerce-se a liberdade de pensamento e de ação dos sujeitos envolvidos, para que os mesmos possam decidir e optar entre as alternativas que lhe são apresentadas, livres de coações internas e externas ${ }^{(9)}$.

A mudança na educação em enfermagem implica, pois, na autonomia dos seus sujeitos para definir estratégias para a articulação entre teoria e prática, para a diversificação dos cenários de aprendizagem, para a articulação da pesquisa com o ensino e com a extensão, para a adoção de metodologias ativas, para a flexibilização curricular e para a apreensão do aluno como sujeito do seu processo de formação.

0 processo de formação de profissionais críticos, criativos, reflexivos, com compromisso político e capazes de enfrentar os problemas complexos que se apresentam na sociedade e, mais especificamente, na área da saúde, pressupõe a autonomia dos sujeitos desse processo de formação, na opção pela utilização de metodologias ativas de ensino-aprendizagem, que possibilitem aos estudantes ocuparem o lugar de sujeitos na construção da sua aprendizagem, tendo o professor como facilitador e orientador. São estratégias que levam em conta a realidade concreta e a necessidade de se trabalhar, além das questões técnicas, as emoções e as relações interpessoais. São metodologias que buscam desenvolver valores e atitudes no processo ensino/aprendizagem, considerando que a prestação do cuidado é realizada por sujeitos portadores de valores, culturas e ideologias que permeiam a prática sanitária desses agentes.
Com base no princípio da Autonomia, os sujeitos envolvidos no processo de formação têm o direito de terem idéias próprias, de fazer escolhas metodológicas, de tomar atitudes na implementação da articulação teoria e prática, da pesquisa com o ensino e com a extensão, na adoção de medidas que contraponham a rigidez curricular, na opção pela diversificação dos campos de práticas, dentre outros. Tudo isto baseado em valores e crenças que norteiam sua concepção de mudança na educação, na saúde e, mais especificamente, na enfermagem. Isto inclui a capacidade para a escolha autônoma do outro, para afastar o medo e outras condições freqüentes no cotidiano do fazer saúde e educação e, conseqüentemente, assumindo a convicção pessoal sobre a importância de uma dada idéia ou comportamento ${ }^{(10)}$.

Essa capacidade, por sua vez, inclui temores e riscos que envolvem a transformação. Muitas vezes, alguns professores temem perder o emprego por praticar a educação emancipadora, ao invés da pedagogia da transferência do conhecimento. Temem, também, o constrangimento de reaprender diante dos estudantes, pois os professores querem sentir-se experimentados e, por isso, a necessidade de se recriar o trabalho intimida a muitos deles ${ }^{(8)}$. Nesse caso, preferem não fazer uso da sua autonomia de cidadão e sujeito do processo da mudança na educação em enfermagem.

Esses temores e riscos são algo de muito concreto e são uma manifestação de que estamos vivos e que temos de analisá-los criticamente e com responsabilidade para recriarmos a nós mesmos e à sociedade. Se os sujeitos do processo de formação profissional não controlam seu medo, eles deixam de arriscar e, conseqüentemente, deixam de criar e sem arriscar não há possibilidade de existir $^{(8)}$.

A educação conservadora, por sua vez, dá pouca autonomia a docentes e discentes para reinventarem, com responsabilidade, o conhecimento existente, ou seja, a responsabilidade para proporcionar, a cada discente, o máximo de oportunidades para o desenvolvimento de saberes, assim como para admitirem que a responsabilidade do processo de formação é também dos discentes.

O princípio da Responsabilidade implica, pois, na preservação da condição de existência da humanidade, mostrando como 0 agir humano é vulnerável, quando se apresenta ante a fragilidade natural da vida. A responsabilidade de cada ser humano para consigo mesmo é indissociável daquela que se deve ter em relação a todos os demais. Trata-se de uma solidariedade que o liga a todos os homens e à natureza que o cerca(11).

Na perspectiva ética, a noção de responsabilidade é vinculada à de liberdade, ou seja, a liberdade e a responsabilidade são fontes do ato ético, assim como a consciência e os valores. Alguém só pode ser responsável por seus atos se é livre e tem consciência deles. 
Outro aspecto da dimensão ética na implementação da mudança na educação em enfermagem é, portanto, a liberdade dos sujeitos do processo de formação, para estimular o pensamento crítico, para questionar o que está escrito, para fazer a crítica ao texto e ao contexto, assim como às práticas pedagógicas e de saúde. A liberdade de fazer a crítica cria uma condição de disciplina intelectual necessária aos docentes e discentes. Assim, a questão não é só apresentar aos alunos numerosos capítulos de livros para serem lidos, mas motivá-los a enfrentarem o texto com olhar crítico e reflexivo.

Através da liberdade do pensamento crítico sobre um texto ou uma prática, tentamos desvendar as intencionalidades dos sujeitos envolvidos, observando as razões pelas quais eles são como são e o contexto político e histórico em que se inserem. $E$ isto se constitui num ato de conhecimento e não em uma mera transferência de conhecimento. A liberdade ilumina a realidade no contexto do desenvolvimento do trabalho intelectual(8).

Os sujeitos desse processo, usando da sua liberdade, responsabilidade e autonomia estabelecem estratégias que indicam o aluno como sujeito do seu processo de formação. Essa opção requer a predominância da formação sobre a informação, em que o ensino é direcionado para o desenvolvimento da capacidade de aprender a aprender; de articular conhecimentos, de desenvolver habilidades e atitudes; de saber buscar informações para resolução de problemas e de enfrentamento a situações de imprevisibilidade; de mobilizar a sua inteligência para fazer face aos desafios do trabalho; de apreender a realidade social e de reconhecer as lacunas do seu conhecimento ${ }^{(2)}$.

A universalização dessas ações educativas, por sua vez, vem exigir solidariedade como valor universal à subsistência individual e coletiva, através da responsabilidade e interesse recíprocos. Solidário é, portanto, aquele para quem a vida não é apenas co-existência com os outros, mas uma verdadeira convivência, um viver com e para os outros.

0 princípio da Solidariedade implica na percepção de interdependência ente todos os seres, de que há uma origem e um destino comuns. Neste sentido, a solidariedade se impõe como uma categoria ôntica e ao mesmo tempo política. A solidariedade ôntica no sentido de que todos somos seres de relação e, por isso, reciprocamente solidários, e uma categoria política desde que a solidariedade ôntica pode ser assumida, conscientemente, num projeto político e constituir o eixo das relações sociais ${ }^{(12)}$.

No exercício da solidariedade, o diálogo é de fundamental importância. 0 diálogo cria relações saudáveis e produtivas para a educação; é o relacionamento existencial eu/tu/nós e é a matriz para os relacionamentos interpessoais ${ }^{(13)}$. 0 diálogo aparece, portanto, como peça fundamental entre os sujeitos envolvidos, para que nenhum desses sujeitos seja um objeto de trabalho, mas sim sujeito da sua cidadania, vendo-se como uma pessoa que vai se construindo na relação com o outro. Docentes, discentes, profissionais e usuários de serviços de saúde se recriam no diálogo, de forma mais ampla, onde cada um é estimulado a pensar e a repensar sobre o pensamento do outro.

Nesse entendimento, o princípio da Alteridade é apresentado como fundamento de toda a reflexão. Isso implica na necessidade dos sujeitos do processo de formação considerarem-se pessoas enquanto estabelecem uma relação de abertura face-a-face com os outros. 0 princípio da alteridade no processo de formação do enfermeiro é 0 eixo condutor das ações pedagógicas, da revelação do outro, da escuta da sua voz e da voz do outro(14).

Através da Alteridade, evita-se impor ao outro a nossa maneira de encarar a verdade. 0 princípio da Alteridade leva os sujeitos do processo de formação a refletirem sobre eles como co-responsáveis por esse processo, objetivando a participação de todos para o bem comum.

0 agir em educação é visto, portanto, como uma atividade solidária na responsabilidade e co-responsabilidade na formação do profissional que a sociedade necessita e merece. 0 fundamento da solidariedade é, pois, 0 senso da Justiça, da dignidade humana, da igualdade e fraternidade entre todos os envolvidos.

A Justiça é parte da consciência de cidadania que obriga as distribuições justas, eqüitativas e universais dos benefícios dos serviços de saúde no processo de formação, dentre outros. Ela busca proporcionalidade natural, liberdade contratual, igualdade social; bem estar coletivo e equidade entre os envolvidos nesse processo e em toda a sociedade. Sua importância está em considerar os modelos de diferentes organizações, em buscar otimizar as conseqüências boas dos atos, o máximo benefício pelo mínimo custo, e quantificar os custos e benefícios. No processo de aprendizagem, o princípio da justiça leva alunos e professores a reconhecerem o que é essencial para o ser humano: liberdade, dignidade, os direitos humanos e a qualidade de vida.

A Justiça no processo de formação implica no desenvolvimento de uma capacidade de percepção e reflexão crítica, ou seja, uma sensibilidade política a tudo aquilo que é inaceitável; implica, portanto, no desenvolvimento de uma capacidade de julgamento e de inserção dos sujeitos do processo de formação, apoiados na sensibilidade individual e coletiva em constante construção e reconstrução dos planos pedagógicos, nos princípios da mudança na educação em enfermagem.

A implementação da mudança na educação em enfermagem se constitui, destarte, num reflexo da aplicabilidade dos princípios éticos que cada sujeito envolvido nesse processo tem como dever lutar por eles, na busca da transformação social.

Implementar a mudança para adequar a formação profissional do enfermeiro à diversidade e complexidade do 
mundo contemporâneo exige, pois, o cumprimento dos princípios éticos na criação e recriação do conhecimento, no estímulo à motivação, no exercício do diálogo, nas atividades de aprendizagem centradas no aluno, dentre outros.

\section{O FAZER ÉTICO QUE INSTRUMENTALIZA A MUDANÇA NO PROCESSO DE FORMAÇÃO DO ENFERMEIRO}

O fazer ético da implementação da mudança na educação em enfermagem, implica na responsabilidade da construção de um sujeito social, de um sujeito cidadão, uma vez que as escolas/cursos têm o desafio de formar um profissional crítico e reflexivo capaz de se inserir na produção dos serviços de saúde na perspectiva da consolidação do SUS.

A intencionalidade da mudança embutida nas DCENF circunscreve um fazer ético voltado para a capacidade de aprender a aprender. Essa capacidade engloba 0 aprender a conhecer, aprender a fazer, aprender a viver junto e aprender a ser, garantindo a capacitação de profissionais com autonomia, responsabilidade, liberdade e discernimento para assegurar a integralidade da atenção à saúde com qualidade, eficiência e resolutividade ${ }^{(2)}$

0 aprender a conhecer está relacionado à liberdade para a descoberta, para a curiosidade, para a busca da compreensão, construção e reconstrução do conhecimento; envolve 0 aprender a pensar a realidade, a pensar o novo, a reinventar o pensar, a pensar e reinventar 0 futuro, com autonomia e responsabilidade. 0 aprender a fazer está relacionado à autonomia para o desenvolvimento da competência pessoal que possibilita ao profissional trabalhar coletivamente, adquirir qualidades para as relações interpessoais no trabalho, em detrimento da pura qualificação profissional, oferecendo oportunidades de desenvolvimento de competências amplas para enfrentar 0 mundo do trabalho. 0 aprender a viver junto oferece possibilidades para o respeito e compreensão do outro, para a busca do esforço comum e para a participação em projetos de cooperação com o outro. 0 aprender a ser integra os outros três pilares e oferecem condições para o desenvolvimento integral da pessoa com inteligência, sensibilidade, sentido ético e estético, responsabilidade pessoal, espiritualidade, pensamento autônomo e crítico, criatividade, iniciativa e rigor científico. Enfim, condições que favoreçam, ao indivíduo, a aquisição de autonomia, discernimento e responsabilidade ${ }^{(2)}$.

O fazer ético na perspectiva da mudança abrange, pois, a dialética do aprender a conhecer, aprender a fazer, aprender a conviver, aprender a ser.
0 aprender a conhecer prioriza o domínio dos instrumentos do conhecimento com vistas a estimular o binômio educando/educador à compreensão do mundo. Esse fazer leva ao despertar da curiosidade, ao senso crítico, à aquisição da autonomia para discernir entre o correto e o incorreto, através de estratégias de ensino-aprendizagem que possibilitem, 0 acesso adequado a metodologias científicas de modo a tornar esses agentes amigos da ciência por toda a vida ${ }^{(15)}$.

0 aprender a fazer explora não só a noção de qualificação, mas a de competência, propondo um trabalho de relação teoria e prática de modo que as(os) alunas(os) em formação ponham em prática os seus conhecimentos. Este segundo pilar implica num fazer ético, num compromisso ético, que proporcione ao sujeitos do processo de formação, uma prática fundamentada e competente ${ }^{(2)}$.

0 aprender a conviver circunscreve-se na liberdade como fundamento do ser humano. Na complexidade da vida humana, a possibilidade de liberdade para conviver é construída a cada momento, na aceitação das determinações das quais não se pode fugir e na luta contra as determinações que podem ser superadas. A vida em sociedade é uma condição humana. Ser homem significa viver junto com outras pessoas. 0 fazer ético do conviver é redesenhado pela qualificação do diálogo entre as inúmeras questões que envolvem o cotidiano do processo de formação, auxiliando na compreensão dos mecanismos invisíveis atuantes nesse processo ${ }^{(2)}$.

0 aprender a conviver constitui um dos desafios da educação profissional. 0 clima altamente competitivo que caracteriza a atividade política, econômica e social no país, e em nível internacional, incentiva a educação a priorizar o espírito competitivo e o sucesso individual. 0 agir ético do aprender a conviver aponta para a necessidade de aprender a conviver na diversidade humana, utilizando-se do confronto através do diálogo e do desenvolvimento da empatia. Aponta, ainda, para a necessidade de formação de profissionais críticos, criativos, reflexivos, com compromisso político e capazes de enfrentar os problemas complexos que se apresentam na área da saúde e na sociedade.

A prática reflexiva tem afinidades com normas, valores, justiça e poder, favorecendo uma forma de sensibilidade, de descentralização ou de método para lidar com as dimensões éticas de sua prática. Todo processo de formação busca contribuir para que os sujeitos reflitam sobre sua prática, de modo a exercerem sua capacidade de observação e análise, com liberdade e responsabilidade social(15).

0 aprender a ser implica na contribuição para o desenvolvimento da pessoa na sua totalidade: inteligência, sensibilidade, sentido estético, responsabilidade pessoal e espiritualidade. Prioriza o desenvolvimento da capacidade de agir da pessoa, com maior autonomia, discernimento 
e responsabilidade social, onde a educação é, ao mesmo tempo, um processo individualizado e uma construção interativa.

Na perspectiva ética, 0 aprender a ser persegue a necessidade da compreensão do ser nas relações que se estabelecem, sem perder de vista os valores morais. Nessa relação, é importante o sentido do cuidar de si mesmo e do outro, quando a pessoa se sente envolvida afetivamente e ligada estreitamente ao destino do outro, consciente do seu valor intrínseco e sua relativa autonomia, emergindo 0 sentido da responsabilidade ${ }^{(3)}$.

0 agir ético que instrumentaliza as mudanças no processo de formação do enfermeiro está envolvido, pois, pelo desenvolvimento da autonomia, liberdade e responsabilidade dos sujeitos, seu senso crítico, sua capacidade de construir e defender um determinado ponto de vista, tanto na sua individualidade como coletivamente.

\section{CONSIDERAÇÕES FINAIS}

De acordo com o exposto, a dimensão ética do fazer cotidiano no processo e formação do enfermeiro fundamenta-se na interface da ética com a educação e se constrói na ação do pensamento crítico, no desenvolvimento da capacidade de reflexão, de análise crítica da sociedade e, mesmo, das próprias relações sócio-educativas dos sujeitos desse processo. Esses sujeitos devem ser apreendidos como pessoas capazes de evoluir, de aprender a aprender, de mobilizar recursos, ativar esquemas, tomar decisões, usufruir a experiência, refletindo sobre o que gostariam de fazer, sobre o que realmente fizeram e sobre o resultado de tudo isso.

Essas ações, por sua vez, englobam uma dimensão relacional, expressando, no plano interno dos sujeitos, o desafio de conviver com as diferenças, além de integrar as partes e 0 todo que estruturam e organizam suas interações com o mundo e consigo mesmo. Engloba, portanto, uma relação inter-pessoal e institucional que envolve a implementação das mudanças sugeridas nas

\section{REFERÊNCIAS}

1. Brasil Ministério da Educação. Conselho Nacional de Educação. Resolução CNE/CES n. 3, de 7 de novembro de 2001. Institui diretrizes curriculares nacionais do curso de Graduação em Enfermagem. Diário Oficial da União, Brasília, 9 nov. 2001. Seção 1, p. 37.

2. Fernandes JD, Xavier IM, Ceribelli MI, Bianco MHC, Maeda $D$, Rodrigues MV. Diretrizes curriculares e estratégias para implantação de uma nova proposta pedagógica. Rev Esc Enferm USP. 2005;39(4):443-9.
DCENF. Autonomia, respeito, tolerância, responsabilidade e compromisso são princípios que regulam as relações entre as pessoas ou as instituições envolvidas no processo formativo.

Pelo exposto, a dimensão ética na implementação da mudança no processo de formação do enfermeiro não se constitui, simplesmente, numa relação consigo mesma. Ela é, ao contrário, a relação com o outro, pressupondo uma atitude ética solidária, a partir do fortalecimento das relações no âmbito coletivo. Ela estimula os sujeitos do processo formativo, ao sentimento de pertencer, de fazer parte, de se sentirem incluídos, questão fundamental para o sentimento de liberdade. 0 grupo, por si só, não garante a solidariedade, pois esta é construída no nosso cotidiano através de uma rede de apoio e num pensar coletivo fundamentado nos princípios da ética. Essa solidariedade não se constitui em algo distante, inalcançável; ela acontece no aqui e agora do nosso cotidiano, em meio aos conflitos e à adversidade.

Pensemos, pois, num processo de formação ético, entendendo-o como um agir educacional pautado na concretude dos sujeitos desse processo, centrado na realidade concreta onde eles se inserem. Um processo onde não se impõem comportamentos, mas potencializa o diálogo, a compreensão, o respeito, a liberdade e a solidariedade. Um agir pautado numa relação entre as noções éticas e as situações vividas pelos sujeitos. Caso contrário, estaremos, apenas, repassando noções abstratas e insuficientes para o pleno exercício dos valores éticos da implementação das mudanças sugeridas nas DCENF.

Finalizando, queremos deixar claro que o presente estudo não pretendeu apresentar fórmulas para 0 agir ético no processo de formação, mas trazer construtos teóricos que possam suscitar 0 debate e esboçar alternativas que indicam a necessidade de transformação da prática do educando/educador e do modelo curricular constituído, apontando elementos que evidenciam a preocupação com a ética no desenvolvimento do Projeto Pedagógico de cada Curso.

3. Xavier IM, Fernandes JD, Ceribelli MI. Diretrizes curriculares: articulação do texto e contexto. Bol Inf Assoc Bras Enferm. 2002;44(2):6-7.

4. Boff L. Saber cuidar: ética do humano - compaixão pela terra. Petrópolis: Vozes; 1999.

5. Santos SSC. Pesquisa em enfermagem à luz da complexidade de Edgard Morin. Rev Bras Enferm. 2003;56(6):687-9. 
6. Gómez AP. 0 pensamento prático do professor: a formação do professor como profissional reflexivo. In: Nóvoa A, coordenador. Os professores e sua formação. 2a ed. Lisboa: Dom Quixote; 1995. p. 95-114.

7. Molina A. Bioética: uma abordagem para iniciantes. In: Molina A, Albuquerque MC, Dias E, organizadores. Bioética e humanização: vivências e reflexões. Recife: EDUPE; 2003. p. 11-24.

8. Freire $P$, Shor I. Medo e ousadia: o cotidiano do professor. Rio de Janeiro: Paz e Terra; 1986.

9. Forte P. Ética e saúde: questões éticas, deontológicas e legais, tomada de decisões, autonomia e direitos do paciente, estudo de casos. São Paulo: EPU; 1998.

10. Beauchamp TL, Childress JF. Principles of biomedical ethics. New York: Oxford University Press; 2001.
11. Lepargneur H. Bioética, novo conceito: a caminho do consenso. São Paulo: CEDAS; 1996.

12. Siqueira JE, Hans J. A ética da responsabilidade. In: Urban CA. Bioética clínica. Rio de Janeiro: Revinter; 2003. p. 36-43.

13. Pessini L, Barchifontaine CP. Problemas atuais de bioética. São Paulo: Centro Universitário São Camilo; 2002.

14. Braga Filho CE. Princípio da justiça. In: Urban CA. Bioética clínica. Rio de Janeiro: Revinter; 2003. p. 27-35.

15. Freire P. Pedagogia da autonomia. Rio de Janeiro: Paz e Terra; 1996. 